\title{
THERMAL ANALYSIS AND MICROSTRUCTURAL CHARACTERIZA- TION OF CERAMIC GREEN TAPES PREPARED BY AQUEOUS TAPE CASTING
}

\author{
A. Şakar-Deliormanlı ${ }^{*}$, E. Çelik and M. Polat \\ ${ }^{1}$ Izmir Institute of Technology, Chemical Engineering Department, Urla, Izmir, Turkey \\ ${ }^{2}$ Dokuz Eylül University, Metallurgy and Materials Engineering Department, Izmir, Turkey
}

\begin{abstract}
In this study, aqueous lead magnesium niobate (PMN) slurry formulations were developed for tape casting using a poly(acrylic acid) - poly(ethylene) oxide comb polymer as the dispersant, nonionic acrylic latex as the binder phase and hydroxypropyl methylcellulose as the wetting agent. Concentrated suspensions were cast onto a silicone-coated mylar film, and the effect of acrylic latex on deposition was investigated.

Thermal analyses were performed to investigate the mass loss of the green tapes as a function of calcination temperature. Differential scanning calorimetric analyses were made under air and nitrogen atmospheres to investigate the binder distribution through the green tapes. Results showed that it is possible to prepare flexible, crack free PMN thick films using a proper slurry composition in the presence of acrylic latex binder, without using any plasticizer. Additionally, decomposing mechanisms of the acrylic based binder were essentially different in the two atmospheres.
\end{abstract}

Keywords: acrylic latex, DSC, lead magnesium niobate, tape casting, TG

\section{Introduction}

Tape casting is a shaping method to produce two-dimensional thin ceramic plates of usually $10-1000 \mu \mathrm{m}$ thickness [1]. A paste-like suspension consisting of powder, solvent, dispersant, binder and plasticizer is cast onto a substrate by a moving blade at a constant distance to the substrate. With today's tape casting technology, very thin tapes can be cast, allowing manufacture of capacitors and transducers for high frequency operation in high-resolution medical imaging [2, 3].

Lead magnesium niobate (PMN) is a typical relaxor ferroelectric material. Because of its high dielectric constant and electrostrictive properties, it finds application in the manufacture of multilayer electronic devices such as capacitors, and actuators $[4,5]$. PMN has a perovskite structure. Other perovskites such as $\mathrm{BaTiO}_{3}$ and $\mathrm{SrTiO}_{3}$ are known for a long time and can also be used as capacitors, thermistors and optoelectric elements [6]. The current state of art technology for the production of PMN multilayer electronic devices generally utilizes organic solvent based processing. However, there is now a trend to move away from organic solvents to water-based systems. On the other hand, there is no detailed investigation for the preparation of aqueous slurry formulations of PMN for use in tape casting process.
In tape casting water soluble binders such as PVA and cellulose can result in high viscosity slips that are difficult to cast. Therefore, several scientists conducted research by using aqueous based acrylic emulsions as binders in ceramic systems [7]. Doreau et al. [8] investigated the processing of aqueous tape casting of alumina with acrylic emulsion binders that have different glass transition temperatures $\left(T_{\mathrm{g}}:-40\right.$ and $\left.10^{\circ} \mathrm{C}\right)$. Smay and Lewis developed an aqueous system for the tape casting of lead zirconate titanate. They investigated the effect of acrylic latex suspensions on this system in the presence of hydroxypropyl methylcellulose [9]. Similarly, Kristofferson and co-workers reported that latex binders yield high solids loading suspensions with the desired rheological behavior for the alumina suspensions [10].

In ceramic firing process the organic matrix is burned out and inorganic components form a dense structure. Burning out the organics is a complex process including the vaporization, decomposition, depolymerization and oxidation [11]. Therefore, thermal analysis may be a useful tool to model the firing process. Additionally, combination of the thermal analysis techniques such as DSC, TG, DTA are the best practical tools for monitoring and optimizing the manufacturing process for elimination of firing defects [12]. Alternative methods such as heating 
Table 1 PMN slurry formulations used for the tape casting

\begin{tabular}{lcccc}
\hline & $\mathrm{R} 1 / \mathrm{mass} \%$ & $\mathrm{R} 1.5 / \mathrm{mass} \%$ & $\mathrm{R} 2 / \mathrm{mass} \%$ & $\mathrm{R} 3 / \mathrm{mass} \%$ \\
\hline PMN & 69.60 & 74.58 & 77.35 & 80.33 \\
Binder (B60-A) & 9.72 & 6.94 & 5.40 & 3.74 \\
PAA/PEO & 0.12 & 0.13 & 0.14 & 0.14 \\
$\mathrm{H}_{2} \mathrm{O}$ & 20.46 & 18.25 & 17.03 & 15.71 \\
Methocel F4M & 0.10 & 0.09 & 0.08 & 0.08 \\
Total & 100 & 100 & 100 & 100 \\
\hline
\end{tabular}

microscopy thermal analysis (HMTA) can also be used to investigate the sintering process of ceramic materials [13].

The aim of this study is to prepare aqueous PMN slurry formulations in the presence of acrylic latex binder and investigate the distribution of the organics through the green tapes as well as the decomposition mechanism under heat treatment.

\section{Experimental}

\section{Materials}

Lead magnesium niobate, $\mathrm{Pb}\left(\mathrm{Mg}_{1 / 3} \mathrm{Nb}_{2 / 3}\right) \mathrm{O}_{3}$, powder (average particle size, d50, $1.8 \mu \mathrm{m}$ and BET surface area of $1.168 \mathrm{~m}^{2} \mathrm{~g}^{-1}$ ) was produced by combustion spray pyrolysis method and provided by Praxair Specialty Ceramics (Woodinville, WA, USA). Polyacrylic acid graft polyethylene oxide comb polymer PAA/PEO (W.R. Grace and CoConnecticut, Cambridge, MA, USA) with a molecular mass of $25800 \mathrm{~g} / \mathrm{mol}$ was employed as the dispersant to prepare highly concentrated stable PMN suspensions. The optimum amount of dispersant necessary to disperse the PMN powders was experimentally determined $\left(4.35 \mathrm{mg} / \mathrm{m}^{2}\right.$ of $\left.\mathrm{PMN}\right)$ in a previous study [14].

The binder used in the study was an aqueous based nonionic acrylic latex emulsion, Rhoplex B-60A (Rohm and Haas Co, Philadelphia, PA) having a glass transition temperature of $6^{\circ} \mathrm{C}$ and a solids loading of 47 mass $\%$. Rhoplex B-60 is an ethyl acrylate methyl methacrylate containing small amount of carboxyl groups. In the study hydroxypropyl methylcellulose (Methocel F4M, DOW Chemicals Co., Midland MI) with a molecular mass of $3500 \mathrm{~g} \mathrm{~mol}^{-1}$ was used as the wetting agent.

\section{Methods}

Suspensions having different binder concentrations were prepared by a multi-step process at a solids loading of 55 vol.\%, and hydroxypropyl methyl- cellulose content of $7 \mathrm{mg} \mathrm{cm}^{-3}$. The slurry compositions used in tape casting are given in Table 1.

In the first step of slurry preparation, highly concentrated PMN suspensions were prepared using PAA/PEO comb polymer. Suspensions were subjected to ultrasonic treatment for 2.30 min with on-off intervals (550 Sonic Dismembrator, Fisher Scientific) to break up the agglomerates in the system. Then suspensions were ball milled for $24 \mathrm{~h}$ to ensure complete adsorption of PAA/PEO onto the powder surface at $\mathrm{pH}$ 9. In the next step latex binder and wetting agent were added to the system and the slurry was further ball milled for $24 \mathrm{~h}$. The suspension $\mathrm{pH}$ was readjusted to 9.0 using $1 \mathrm{M} \mathrm{NH} 4 \mathrm{OH}$. The slurry was defoamed for 15 minutes using a planetary centrifugal mixer (Thinky ARE-250, Japan) prior to the tape casting.

PMN films were prepared using laboratory type tape caster (Cladan Inc.Model 133, Serial 181, USA). The slurry was cast onto a silicone coated poly (ethylene terephthalate) stationary film (Mylar, PET blend EI-8526, Douglas-Hanson, Hammond, WI). The casting rate was $25 \mathrm{~mm} \mathrm{~s}^{-1}$ over a length of $1 \mathrm{~m}$. Doctor blade head having width of $100 \mathrm{~mm}$ was set at a height of 30 to $500 \mu \mathrm{m}$. After deposition tapes were allowed to dry in air at $25^{\circ} \mathrm{C}$ for $24 \mathrm{~h}$.

Dried PMN films were sintered at $1000^{\circ} \mathrm{C}$ in an electric furnace to achieve a higher density. For this purpose the binder was burnt out by heating the samples from room temperature to $350^{\circ} \mathrm{C}$ at a rate of $1{ }^{\circ} \mathrm{C} \mathrm{min}^{-1}$, and held at this temperature for $1 \mathrm{~h}$. It was followed by heating to $1000^{\circ} \mathrm{C}$ at a rate of $1^{\circ} \mathrm{C} \mathrm{min}$ and held for $2 \mathrm{~h}$. During heat treatment, alumina crucible system with cover was utilized in order to prevent the lead loss from the samples. To provide a lead rich atmosphere lead zirconate $\left(\mathrm{PbZrO}_{3}\right)$ powder bed was used inside the crucible.

Organic content of the green tapes were analyzed using a differential scanning calorimeter DSC 2920 Modulated, TA Instruments) under air flow and another calorimeter (DSC-50, Shimadzu, Japan) under nitrogen flow $\left(40 \mathrm{~cm}^{3} \mathrm{~min}^{-1}\right)$. To investigate the binder distribution through the entire length of the dried tape, an array of samples were cut 
from the tapes in parallel and perpendicular to casting direction. DSC analyses were performed between $25-600^{\circ} \mathrm{C}$ at a heating rate of $10^{\circ} \mathrm{C} \mathrm{min}^{-1}$. Mass loss was analyzed using a thermogravimetric analyzer (TGA, Setaram Labsys) up to $1000^{\circ} \mathrm{C}$ at a heating rate of $5^{\circ} \mathrm{C} \mathrm{min}^{-1}$ under air atmosphere with a flow rate of $2.5 \mathrm{dm}^{3} \mathrm{~h}^{-1}$. Microstructure of the green and sintered tapes were investigated by scanning electron microscope (Philips, XL-30S FEG).

\section{Results and discussion}

\section{Drying characteristics}

During drying biaxial stresses may develop in ceramic films. As the solvent evaporates the film shrinks freely in the direction of the z-axis while shrinkage in the $x-y$ plane is constrained due to strong adhesion to the casting substrate. This results in a residual stress on the film $[15,16]$. These stresses cause formation of cracks unless relatively large amounts of organic binders are added. On the other hand, presence of organic additives in large quantities may cause other defects such as carbon contamination, large pore volumes or delamination during heat treatment [17]. Therefore it is crucial to adjust the binder content in tape casting slurries and observe its effect on the drying step. Figure 1 shows the pictures of PMN green films having different slurry compositions. Figure 1B depicts the cracks formed during drying period for the film having a composition of R1. At higher binder content, such as slurry R1.5 perpendicular cracks were observed on the surface of the film with respect to casting direction. Pictures also reveal the effect of film thickness on the crack formation. For the film prepared

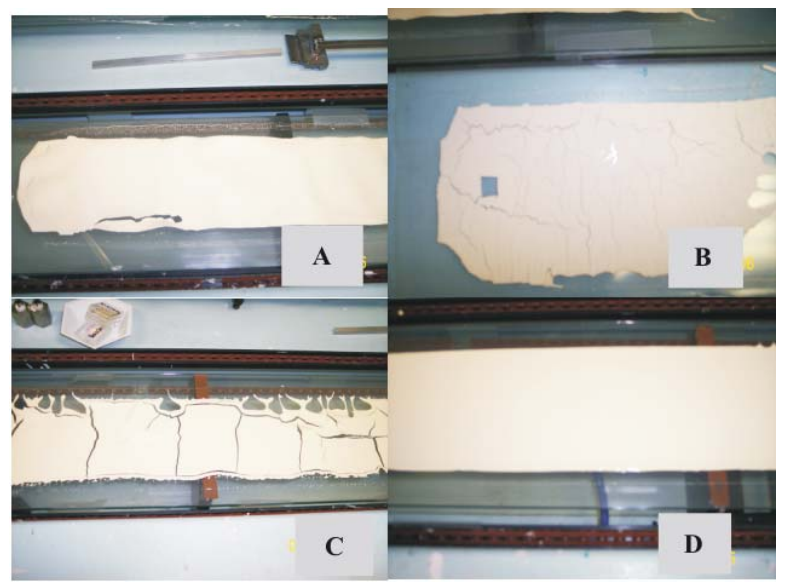

Fig. 1 Pictures of PMN green films having different binder composition. Total solids concentration 55 vol. $\%$, HPMC content $7 \mathrm{mg} \mathrm{mL}^{-1} \mathrm{~A}-\mathrm{R} 1.5,500$; B - R2, 300; C - R1.5, 300; D - R1, $300 \mu \mathrm{m}$ from a slurry composition of R2, drying cracks were observed as it is shown in Fig. 1C. However, in the case of films produced from slurry R1.5 less cracks and more buckling were observed for samples having thickness of $500 \mu \mathrm{m}$ compared to the samples with thickness of $300 \mu \mathrm{m}$ (Fig. 1A). In the study, PMN films prepared from the slurry having a composition of R1 did not show any significant defects during drying period (Fig. 1D).

\section{Thermal analysis of the green tapes}

Figure 2 shows the TG analysis of the samples having different binder concentrations. Results showed that mass loss occurs mainly between 300 to $400^{\circ} \mathrm{C}$ due to removal of the organic phases. Above $400^{\circ} \mathrm{C}$ the mass of the samples remains nearly constant. As expected, mass loss of the samples showed a strong dependence on the binder content of the films. Mass loss was about $10 \%$ for the film prepared from a slurry composition of R1. Similarly, mass loss was measured to be 7.2 and $5.2 \%$ for the samples having a composition of $\mathrm{R} 1.5$ and $\mathrm{R} 2$, respectively.

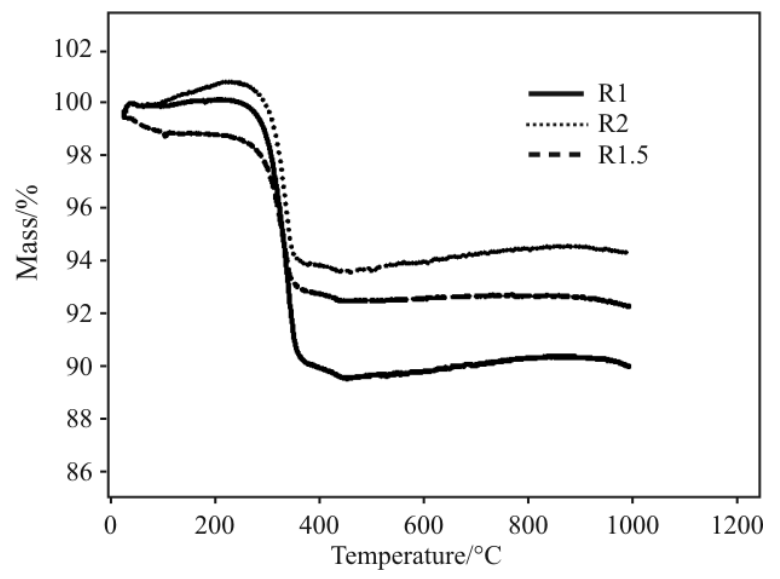

Fig. 2 TG analysis of the PMN films having different binder content

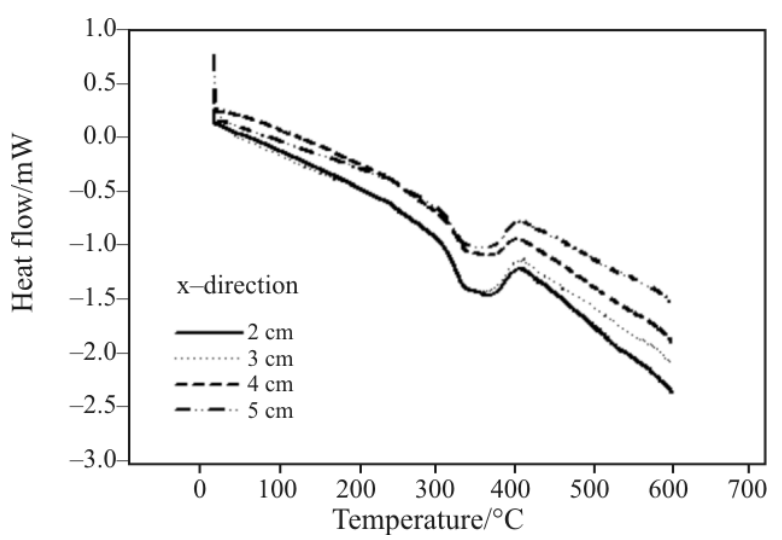

Fig. 3 DSC curves of the PMN films (in nitrogen atmosphere), samples from perpendicular to casting direction, composition R1, and $300 \mu \mathrm{m}$ 


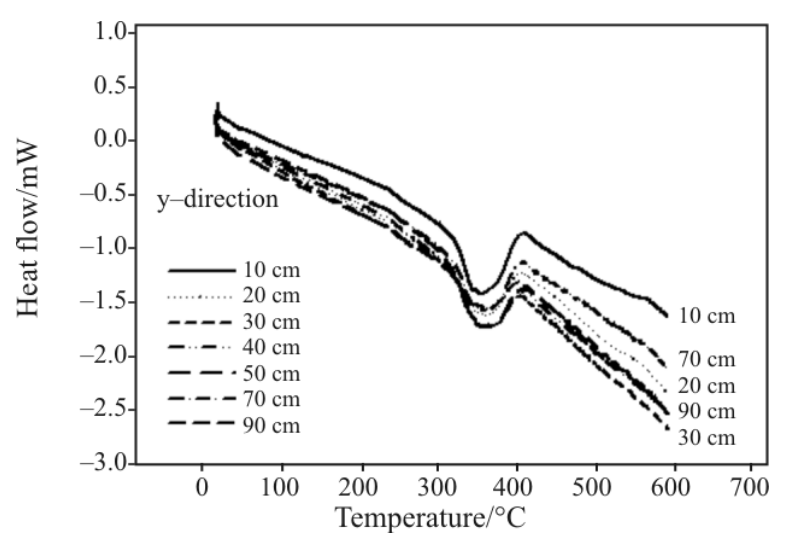

Fig. 4 DSC curves of the PMN films (in nitrogen atmosphere), samples from parallel to casting direction, composition $\mathrm{R} 1$, and $300 \mu \mathrm{m}$

Figures 3 and 4 show the DSC analysis results of the samples performed under nitrogen atmosphere through the length of the film in parallel and perpendicular to the casting direction. For these measurements array of samples were cut in $10 \mathrm{~cm}$ intervals in $y$ direction and in $1 \mathrm{~cm}$ intervals in $x$ direction and analyzed by DSC to investigate the distribution of organics through the film. Results indicate that the binder distribution across the length of the film is generally homogeneous in both directions. On the other hand, small differences observed may be attributed to the non-uniform film thickness through the film length. As it was discussed previously the homogeneous distribution of the slurry contents has very important effects on the final properties of the ceramics. Therefore, a uniform binder distribution must be assured during tape casting since nonuniform distribution of binders may cause defects during sintering step.

DSC curves of PMN green sheets in air atmosphere are shown in Figs 5 and 6. Figure 5 indicates the effect of binder composition and Fig. 6 demonstrates the binder distribution through the film. Results

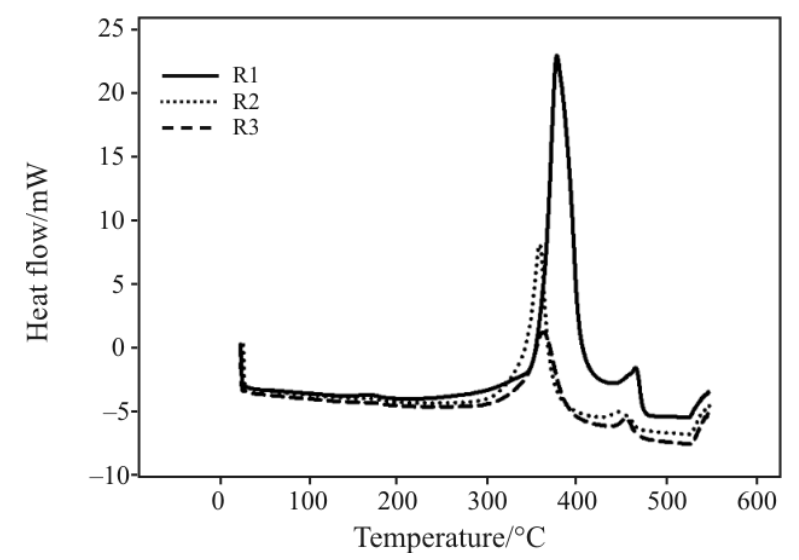

Fig. 5 DSC curves of the PMN films (in air atmosphere) having different binder content

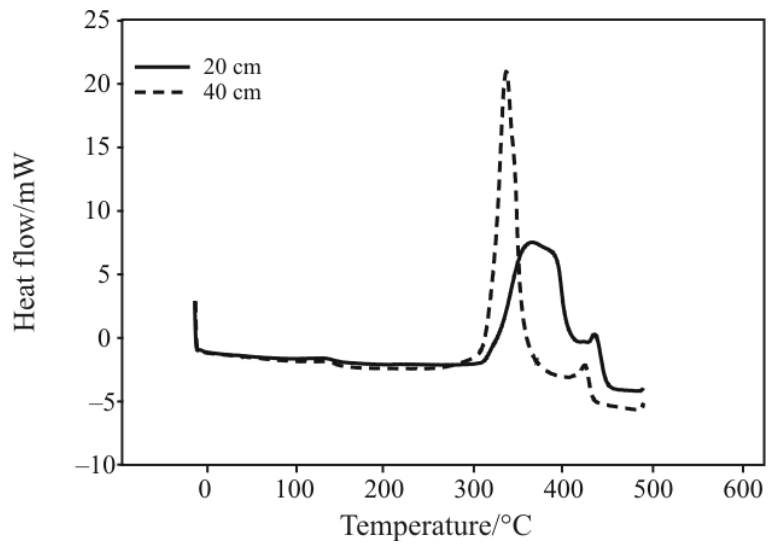

Fig. 6 DSC curves of the PMN films (in air atmosphere), samples from parallel to casting direction, composition $\mathrm{R} 1$, and $300 \mu \mathrm{m}$

revealed that exothermic peaks appeared in air, but endothermic peak was observed in nitrogen atmosphere. In air, organic additives can mainly be oxidized into $\mathrm{CO}_{2}$ and water, which was an exothermic reaction [18]. In latex binders, organic groups such as surfactants are critical group of components, necessary to create the micelles for particle formation and long-term particle stabilization. Common surfactants used in these systems are non-ionic (eg. alkyl phenol ethoxylates) and anionic (eg. sodium lauryl sulfate or dodecylbenzene sulfonate) that are typically added at 2 to 6 mass\%. Protective colloids also contribute to steric stabilization and water-soluble natural or synthetic polymeric emulsifiers such as hydroxyethylcellulose and polyvinyl alcohol, are added in 1 to 10 mass $\%$ [19].

On the other hand, Figs 3 and 4 showed that in $\mathrm{N}_{2}$ atmosphere organic additives could only be degraded into small molecules step by step, which was an endothermic reaction. These results revealed that the decomposing mechanisms of the acrylic based binder were essentially different in the two atmospheres.

\section{Microstructural characterization}

Figures $7 \mathrm{a}$ and $\mathrm{b}$ show the microstructure of the top and the bottom surface of the PMN green film prepared from the slurry composition of R1. Results show that there is no significant difference between the top and the bottom surface of the green PMN film (casting thickness $300 \mu \mathrm{m}$ ), which means that there is no particle segregation. Similarly, cross section of the PMN films having different thicknesses are shown in Figs 7c and d. Accordingly, the lowest film thickness was $\sim 10 \mu \mathrm{m}$ in green state (casting thickness $30 \mu \mathrm{m}$ ). On the other hand, highest film thickness obtained in the study was $265 \mu \mathrm{m}$ corresponding to the sample having a casting thickness of $500 \mu \mathrm{m}$. In the study, 


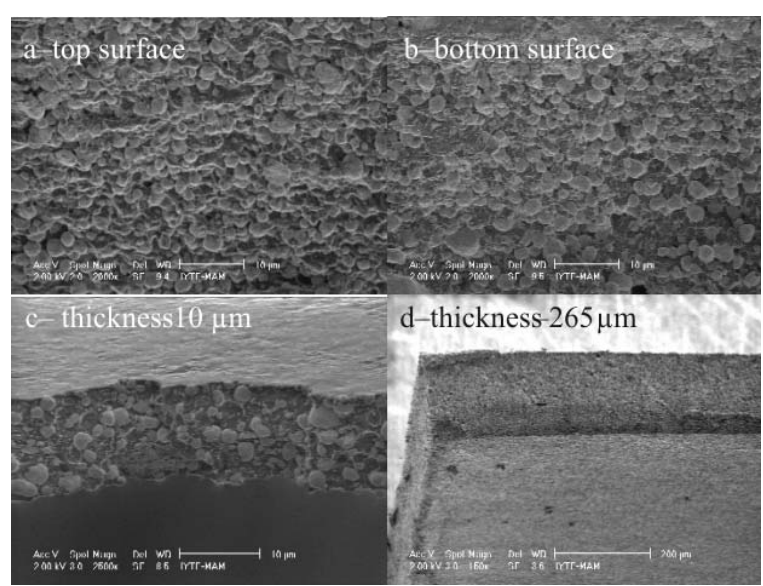

Fig. 7 SEM micrographs of the surface of the PMN film in green state $(300 \mu \mathrm{m}) \mathrm{c}, \mathrm{d}$ - cross sections, composition R1

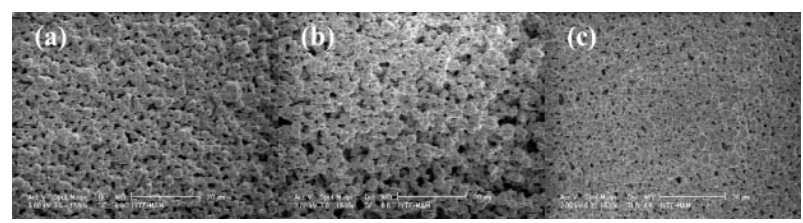

Fig. 8 Microstructures of the PMN films sintered at $1000^{\circ} \mathrm{C}$; $a-R 1, b-R 1.5, c-R 2$

densities of the green tapes were calculated by measuring the dimensions of the samples. The theoretical densities of the dry films were calculated to be $58-60 \%$ prepared from the compositions of $\mathrm{R} 1$.

Figure 8 shows the microstructure of the PMN films after a heat treatment at $1000^{\circ} \mathrm{C}$. SEM micrographs indicate the influence of binder content on the final microstructure of the PMN films. Accordingly, samples sintered at $1000^{\circ} \mathrm{C}$ for $2 \mathrm{~h}$ have a porous structure. As expected a decrease was observed in the porosity as the binder concentration decreased.

\section{Conclusions}

Aqueous PMN slurry formulations were successfully developed for the aqueous tape casting. Results revealed that it is possible to prepare flexible, crack free PMN thick films using a proper slurry composition in the presence of acrylic latex binder without using any plasticizer. Decomposition mechanisms of the acrylic latex binder were essentially different in the air and nitrogen atmospheres. Exothermic peak appeared in DSC analysis was attributed to the oxidation of organic additives in aqueous PMN slurry. On the other hand, endothermic peak were observed in nitrogen atmosphere. SEM analysis of the green tapes demonstrated that the structures are homogeneous and there is no particle segregation.

\section{Acknowledgements}

The authors would like to thank Prof. Dr. Jennifer A. Lewis for her support and use of the laboratory facilities at University of Illinois at Urbana Champaign, USA and supplying the chemicals used in the study. The NATO-A2 bursary of the Scientific and Technological Research Council of Turkey (TUBITAK) is acknowledged.

\section{References}

1 P. L.Meier, L. Urech and L. J. Gauckler, J. Eur. Ceram. Soc., 24 (2004) 3753.

2 A. Safari, M. Allahverdi and E. K. Akdogan, J. Mater. Sci., 41 (2006) 177.

3 T. Tian, D. Jiang, J. Zhang and Q. Lin, J. Eur. Ceram. Soc., 27 (2007) 2671.

4 S. Fengbing, L. Qiang, Z. Haisheng, L. Chunhong, Z. Shix and S. Dezhong, Mater. Chem. Phys., 83 (2004) 135.

5 H. S. Tzou, H. J. Lee and S. M. Arnold, Mech. Adv. Mater. Struct., 11 (2004) 367.

6 J. Luxová, P. Šulcová and M. Trojan, J. Therm. Anal. Cal., 93 (2008) 823.

7 Y. Zhang and J. Binner, J. Mater. Sci., 37 (2002) 1831.

8 F. Doreu, G. Tari, C. Pagnoux, T. Chartier and J. M. F. Ferreira, J. Eur. Ceram. Soc., 18 (1998) 311.

9 J. E. Smay and J. A Lewis, J. Am. Ceram. Soc., 84 (2001) 2495.

10 A. Kristofferson and E. Carlström, J. Eur. Ceram. Soc., 17 (1997) 289.

11 D. Schultze and W. A. Schiller, J. Thermal Anal., 52 (1998) 211.

12 A. Bhattacharya, J. Thermal Anal., 49 (1997) 1365.

13 J. Dweck, L. C. Morais, M. V. A. Fonseca, V. Campos and P. M. Büchler, J. Therm. Anal. Cal., published online, DOI: 10.1007/s10973-008-9115-y.

14 A. Şakar-Deliormanl, J. A. Lewis, E. Çelik and M. Polat, $10^{\text {th }}$ Conference and Exhibition of European Ceramic Society, Berlin 2007.

15 J. A. Lewis, J. Am. Ceram. Soc., 83 (2000) 2341.

16 G. W. Scherer, J. Am. Ceram. Soc., 73 (1990) 3.

17 R. C. Chiu, T. J. Garino and M. J. Cima, J. Am. Ceram. Soc., 76 (1993) 2257.

18 X. Luo, J. Li, B. Zhang, W. Li and H. Zhuang, J. Am. Ceram. Soc., 89 (2006) 836.

19 E. Jablonski, T. Learner, J. Hayes and M. Golden, Tate paper (2004) 1.

DOI: 10.1007/s10973-008-9364-9 